Dicle University Journal of Engineering (DUJE)

web: http://dergipark.gov.tr/dumf

Araştırma Makalesi / Research Article

\title{
Kablosuz Algılayıcı Ağlarında Heterojen Hibrid Kümeleme Modeli
}

\section{Heterogeneous Hybrid Clustering Model in Wireless Sensor Networks}

\section{Sercan YALÇIN ${ }^{*}$, Ebubekir ERDEM²}

1, Fırat Üniversitesi, Bilgisayar Mühendisliği Bölümü, Elazı̆̆,23119, Türkiye, ORCID: 0000-0003-1420-2490, svancin@ firat.edu.tr

${ }^{2}$ Fırat Üniversitesi, Bilgisayar Mühendisliği Bölümü, Elazı̆̆,23119, Türkiye, ORCID: 0000-0001-7093-7016, aberdem@ @irat.edu.tr

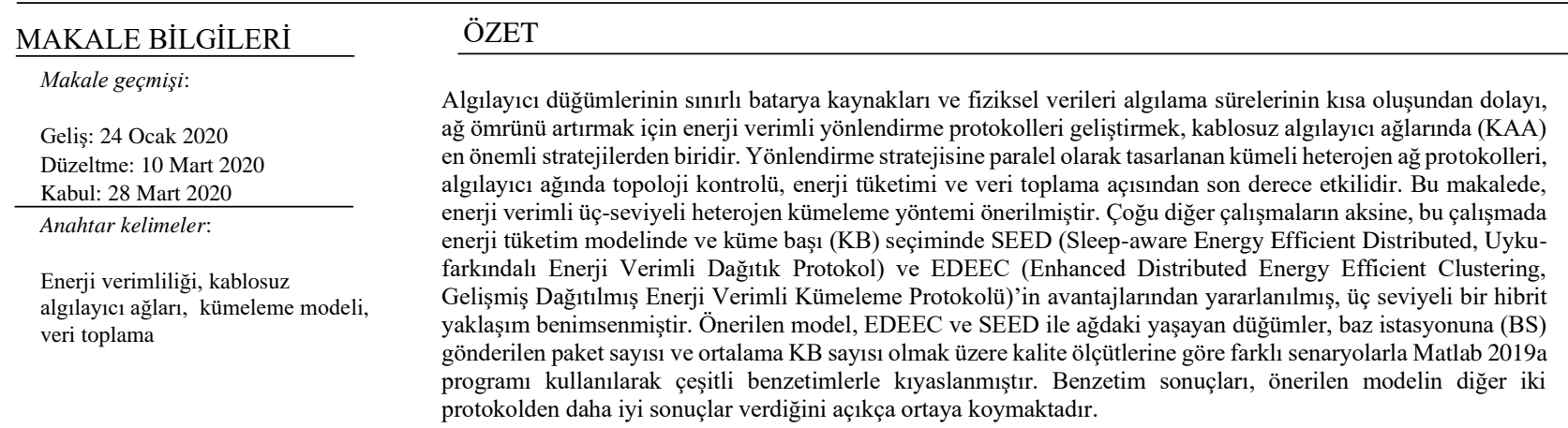

\begin{tabular}{|c|c|}
\hline ARTICLE INFO & ABSTRACT \\
\hline Article history: & \multirow{6}{*}{$\begin{array}{l}\text { Due to the limited battery resources of sensor nodes and the short sensing time of physical data, developing energy } \\
\text { efficient routing protocols to increase network life is one of the most important strategies in wireless sensor } \\
\text { networks (WSN). Clustered heterogeneous network protocols designed in parallel with the routing strategy are } \\
\text { highly effective in terms of topology control, energy consumption and data collection in the sensor network. In } \\
\text { this article, an energy efficient three-level heterogeneous clustering method is proposed. Unlike most other } \\
\text { studies, in this study, the advantages of Sleep-aware Energy Efficient Distributed, SEED) and Enhanced } \\
\text { Distributed Energy Efficient Clustering, EDEEC) are utilized, and a hybrid approach is adopted in the energy } \\
\text { consumption model and cluster head (CH) selection. The proposed model was compared with EDEEC and SEED } \\
\text { protocols using Matlab 2019a program with different simulation scenarios based on quality criteria, including the } \\
\text { living nodes in the network, the number of packets sent to the base station (BS) and the average number of CHs. } \\
\text { The simulation results make it clear that the proposed model gives better results than the other two protocols. }\end{array}$} \\
\hline Received: $24 \mathrm{Ja}$ & \\
\hline Revis & \\
\hline Accepted: 28 March 2020 & \\
\hline Keywords: & \\
\hline $\begin{array}{l}\text { Energy efficiency, wireless } \\
\text { sensor networks, clustering } \\
\text { model, data collection }\end{array}$ & \\
\hline
\end{tabular}

* Sorumlu yazar / Correspondence

Sercan Yalçın

$\bowtie$ svancin@firat.edu.tr 


\section{Giriş}

Kablosuz algılayıcı ağlar (KAA), veri algılama, hesaplama ve kablosuz kanal iletişim yetenekleri sayesinde veri iletimi yapabilen küçük boyutlu algılayıcı düğümleri içerir [1-3]. KAA'lardaki önemli problemlerden biri algilayıc1 düğümlerindeki pil gücünün sınırlı olmasıdır. Dolasıyla, KAA'lardaki çalışma konularında yönlendirme protokolleri önemli bir alandır. Algılayıcı dügüumlerinin ömrünün artırılmasına ilaveten, var olan enerjiyi KAA'ya dengeli olarak dağıtmak da arzu edilen amaçlar arasındadır. Algılayıcı dügümlerdeki sınırlı güç kaynağ 1 nedeniyle, enerjinin mümkün olduğunca daha az tüketilmesi KAA'larda önemli görev teşkil etmektedir. Veriler algılayıcı düğümleri üzerinden diğer düğümlere iletilirken maksimum enerji kullanılır [4-6]. Bütün bu sebeplerden ötürü bir algılayıcı ağı ömrünü uzatmak hedefli yönlendirme algoritmaları geliştirmek için bir dizi araştırma yapılmıştır. Algılayıcı ağlarının ömrünü uzatmak için algılayıcı ağlarının enerji tasarrufu ve ölçeklenebilirliği sağlayarak algılayıcıların ortak çalışması prensibine kümeleme denilmektedir. $\mathrm{Bu}$ anlamda KAA'daki dügüumler kümelere ayrılarak işbirliği içerisinde çalışırlar [7]. Bir küme içerisinde küme lideri olarak bir küme başı $(\mathrm{KB})$ ve üye düğümler bulunmaktadır. Üye düğümler ait oldukları KB'lere çevreden topladıkları verileri tek-atlamalı veya çok-atlamalı tutumla gönderirler. KB'ler elde ettikleri toplam verileri baz istasyonuna (BS) teslim ederler. Sonuç olarak Şekil 1'deki gibi bir ağ döngüsü oluşmuş olur. Şekil 1'de normal, gelişmiş ve süper dügümler olmak üzere 3 seviyeli kümeli ve heterojen ağ modeli verilmiştir.

KAA'lar homojen ve heterojen ağlar olmak üzere iki tür ă modeline sahiptir. Homojenlik, KAA'larda algılayıcı düğümlerinin hem fiziksel hem de yazılımsal özelliklerinin aynı olması anlamına gelmektedir. Heterojenlik ise, ağ düğümlerinin birbirinden farklı olmasıdır. Genellikle araştırmacılar, heterojenliği düğüm enerji seviyelerinin farklı olmasında kullanırlar. Homojen tabanlı algoritmalar enerji tüketimi ve yayılımı, KB seçimi gibi konularda çok verimli çalışmadığından dolayı heterojen KAA'lar geliştirilmiştir.

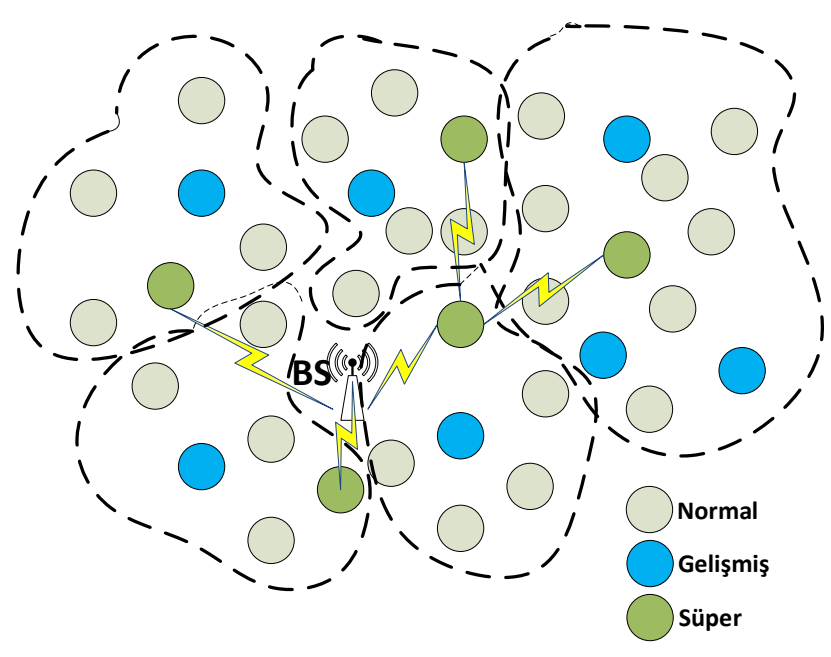

Şekil 1. Kümeli heterojen ă̆ yapısı

\section{Figure 2. A clustered heterogeneous network structure}

Bu çalışmada, üç seviyeli heterojen KAA için bir kümeleme yöntemi önerilmektedir. Önerilen yöntem EDEEC (Enhanced Distributed Energy Effficient Clustering, Gelişmiş Dağıtılmış Enerji Verimli Kümeleme Protokolü) [8] yöntemindeki gibi üç seviyeli KB seçim olasılık parametresi ve enerji modeline sahiptir. Ayn zamanda, SEED (Sleep-aware Energy Effficient Distributed, Uyku-farkındalı Enerji Verimli Dağıtık Protokol) [9] protokolündeki gibi uykufarkındalı veri iletimi ve alımı modeline sahiptir. Aslında önerilen yöntem, bu iki protokollerin üstün yönlerini kullanan bir hibrit tekniği esas almaktadır. Önerilen yöntem, EDEEC ve SEED protokolleriyle performans karşılaştırması yapılmıştır.

\section{İlgili Çalışmalar}

KAA'lar için literatürde birçok kümeleme algoritmaları önerilmiştir.

$\mathrm{Bu}$ algoritmalarından en eski olanı LEACH (Low Energy Adaptive Clustering Hierarchy, Düşük Enerji Uyarlamalı Kümeleme Hiyerarşisi) [10], ağ içerisine rastgele dağıtılan algilayıcı düğümlerden rastgele bir KB seçerek kümeleme yapısı oluşturur. KB'ler tek-atlamalı veya çokatlamalı yönlendirmeyle diğer düğümlerden topladıkları verileri BS'ye iletir.

Bir çalışmada, Lindsey ve Raghavenda [11] LEACH'in bir gelişmişi ve zincir temelli bir protokol olan PEGASIS'i (sensör bilgi 
sistemlerinde güç verimli toplama) önermiştir. PEGASIS'te, her bir dügüm sadece yakın bir komşu ile iletişim kurar ve BS'ye sırasıyla verileri iletir, böylece tur başına harcanan enerji miktarını azaltır.

Bir çalışmada, Singh vd. [12] LEACH tabanlı yeni bir yönlendirme algoritması önermiştir. $\mathrm{Bu}$ algoritmanın kümeleme mekanizmasında optimizasyon yöntemi kullanılmaktadır.

Bir çalışmada, Younis ve Fahmy [13], HEED (Hibrid Enerji-Verimli Dağıtılmış kümeleme) protokolünü önermiştir. $\mathrm{Bu}$ protokole göre, KB'ler, dügüumlerin kalan enerjisi, komşuları veya dügüm derecesi gibi ikincil bir parametreye göre periyodik olarak seçilmektedir. HEED, düşük mesaj yükü oluşturur ve ağ genelinde oldukça eşit $\mathrm{KB}$ dağıtımı gerçekleştirir.

Bir çalışmada, Smaragdakis vd. [14], algılayıcı ağından geri bildirimin güvenilir olması gereken birçok uygulama için çok önemli olan ilk dügümün ölümünden önceki zaman aralığını uzatmak için (kararlılığı artırmak için) SEP adında, heterojen farkındalı bir protokol önermiştir. SEP, her bir düğümde kalan enerjiye göre her düğümün ağırlıklı seçim olasılıklarına dayanan bir KB seçim algoritması sunmaktadır.

Bir çalışmada, Quing ve Zhu [15], DEEC adı verilen heterojen KAA'lar için yeni bir dağıtılmış enerji tasarruflu kümeleme şeması önermiştir. DEEC'de KB'ler, her bir düğümün kalan enerjisi ile ağın ortalama enerjisi arasındaki orana dayalı bir olasılıkla seçilir. Düğümler için $\mathrm{KB}$ olma dönemleri başlangıç ve kalan enerjilerine göre farklıdır. DEEC protokolünü iki seviyeli heterojen ağ modeli ile sunmuşlardır. Ancak araştırmacılar bu protokolü çok-seviyeli olarak geliştirmişlerdir.

Bir çalışmada, Saini ve Sharma [8], ağın ömrünü ve kararlılığını artırmak için üç tip düğüm için DEEC türevli EDEEC protokolünü önermiştir. $\mathrm{Bu}$ algoritma, ağın heterojenliğini ve enerji seviyesini arttırır. Daha sonraları araştırmacılar [16-17], DEEC türevli üç seviyeli heterojenliği destekleyen birçok protokol sunmuşlardır.

Bir çalışmada [9], yazarlar SEED olarak adlandırılan Uyku-Uyanık Enerji Verimli Dağıtılmış kümeleme ve yönlendirme protokolü önermiştir. Bu protokolde, ağ algılama alanını üç enerji bölgesine bölünür, çünkü SEED protokolünde KB'ler BS'yle doğrudan iletişim kurar. Yüksek enerji bölgesinin KB'leri, BS ile daha uzun bir mesafeden iletişim kurar ve düşük enerji bölgesinin KB'lerine kiyasla ekstra enerji maliyetine sebebiyet verir.

Bir çalışmada [18], (Vançin ve Erdem, 2017), SEED (uyku-uyanık enerji dengeli dağıtılmış) algoritması, homojen algılayıcı ağları için LEACH, mod-LEACH ve PEGASIS ve heterojen algılayıcı ağları için SEP, DEEC ve CEEC gibi kümeleme yöntemleri ile karşılaştırılmıştır.

Bir çalışmada [2], yazarlar enerji etkin üç seviyeli heterojen kümeleme yöntemi (DEEC) tabanlı dağıtık enerji verimli kümeleme protokolü önerilmiştir. Çoğu diğer çalışmaların aksine, bu çalışmada enerji tüketim modelinde örneklemeli denge tabanlı eşik değerin etkisini göz önüne alınmaktadır.

Bir çalışmada, Gambhir vd. [19] KAA için yapay arı koloni algoritması tabanlı kümeleme yöntemi önermiştir.

\section{Materyal ve Yöntem}

Önerilen yaklaşım, SEED protokolü temelli veri iletimi, alımı ve toplanmasını esas almaktadır. KB seçimi için harcanan enerji bakımından SEED protokolünü benimserken üç seviyeli heterojen $\mathrm{KB}$ seçim olasılığının belirlenmesi bakımindan ise EDEEC protokolüne benzemektedir. $\mathrm{Bu}$ bakımdan önerilen yöntem, hibrid bir protokoldür.

KAA'da dağıtılan algılayıcı düğümleri aynı verileri BS'ye iletebilmektedir. Bu şekilde alıcı dügü̈mde (BS) fazlalık veriler oluşabilmektedir. $\mathrm{Bu}$ sorunu çözmek için, bu yönlendirme protokolünde iki veya daha fazla algılayıcı düğümü aynı uygulama tarafından ve birbirinin iletim aralığında alt kümeler oluşturur. Bir alt kümede, yalnızca bir algılayıcı düğümü uyanık olur ve KB'ye veri elde edilen yönlendiriciler ve algılayıcı düğümlerinin geri kalanı pil kaynaklarını korumak için uyku modunda kalır. $\mathrm{Bu}$ şekilde uyanık modlu veri iletme ve toplama işlemi gerçekleştirilerek enerji tüketimi ve veri çakışma olasılığı azaltılmış olur [2,9]. Önerilen 
model, bahsedilen tüm protokollerle karşılaştırıldığında büyük bir veri iletim gücüne sahiptir.

\section{Önerilen Yöntemin Kurulum Fazı}

Algılayıcı ağının kurulum aşamasında, her algılayıcı düğümü komşularına uyarı mesajını iletir. Bu uyarı mesajları dugum_id, uygulama türü, komşu sayısı ve konumunu içerir. $\mathrm{Bu}$ anlamda, tüm algılayıcı dügüumleri yönlendirme tablolarını kaydeder ve uygulama türüne ve iletişim aralığına bağlı olarak alt kümeleri oluşturur.

\section{Önerilen Yöntemin Ă̆ ve Enerji Modeli}

Önerilen yöntem, EDEEC protokolü ile benzer heterojen ağ yapısına sahip olup KB seçimi ve bu işlem için harcanan enerji modeli olarak ise SEED protokolüne benzemektedir.

Heterojen KAA'lar, enerji seviyeleri, donanım yapısı ve diğer özel özelliklerle ilgili olarak iki, üç veya çok sayıda algılayıcı düğümünden oluşabilir ve sırasıyla iki, üç veya çok düzeyli dağıtık heterojen KAA olarak tanımlanabilir $[8,9]$.

Önerilen protokol, algılayıcı düğümlerinin normal, gelişmiş ve süper batarya seviyesine sahip olduğu düşünülen üç seviyeli heterojen KAA'yı esas almaktadır. Ancak önerilen yöntem için çok-seviyeli heterojenlik de düşünülebilir. $E_{0}, E_{0}(1+a)$ ve $E_{0}(1+b)$ sirasiyla normal, gelişmiş ve süper algılayıcı dügüumünün başlangıç enerjisini ifade etmektedir. Gelişmiş düğümün normal düğümlerden, gelişmiş dügüumlerin de süper dügüumlerden kaç kat fazla enerjiye sahip olduğunu sirasıyla $a$ ve $b$ katsayıları belirlemektedir. Dügüumlerin toplam enerjileri hesaplanırken $f, f_{0}$ ve $f_{1}$ kesir katsayıları dikkate alınmalıdır. $N$, ağdaki toplam düğüm sayısı olduğu için ağdaki normal, gelişmiş ve süper dügümlerin sayıları sirasıyla $N_{n m l}, N_{a d}$ ve $N_{\text {sup }}$ olmaktadır.

KAA'daki normal dügümlerin toplam ilk enerjisi $E_{n m l}$ denklem (1) 'de verilmiştir.

$E_{n m l}=N_{n m l}(1-f) E_{0}$

KAA'da gelişmiş düğümlerin toplam ilk enerjisi $E_{a d}$ denklem (2) 'de verilmektedir.
$E_{a d}=N_{a d}\left(1-f_{0}\right) E_{0}(1+a)$

KAA'da süper dügümlerin toplam ilk enerjisi $E_{\text {sup }}$ denklem (3) 'de verilmektedir.

$$
E_{\text {sup }}=N_{\text {sup }}\left(1-f_{1}\right) E_{0}(1+b)
$$

Böylece, üç seviyeli heterojen KAA'ların toplam ilk enerjisi denklem (4) 'te verilen şekildeki gibi hesaplanır.

$E_{\text {total }}=E_{n m l}+E_{a d}+E_{\text {sup }}$

$\mathrm{KB}$, algılayıcı düğümleri ve diğer üye düğümlere kıyasla daha fazla enerjiyi tüketir. Birçok turdan sonra, tüm algılayıcı düğümlerinin enerji seviyesi birbirine kıyasla değişir. $\mathrm{Bu}$ nedenle, heterojenliği işleyen bir kümeleme ağ protokolü, homojen ağ protokolünden daha önemlidir $[2,8]$.

Bir alg1layıcı düğümünün enerji tüketmesi, toplanan verilerin algılanması, işlenmesi ve kablosuz iletişim gibi özel işlevleri yerine getirebilmesi için enerji tüketimini göz önünde bulunduran modelleri ihtiva eder. $\mathrm{Bu}$ modeller enerji tüketim hesaplamaları yapmakla sorumludur. Önerilen model için, KB seçimi yapılırken ağın ortalama enerjisine ilave olarak düğümlerin başlangıç ve kalan enerjisine bağımlı olasılıklar fikrini içerir. Ağın $r$.tur için ortalama enerjisi denklem (5) olarak verilir.

$E_{\text {avg }}=\frac{1}{N} E_{\text {total }}\left(1-\frac{r}{R}\right)$

$R$, ağ ömrü boyunca toplam tur sayısını belirtir ve denklem (6) olarak verilir. $E_{\text {round }}$ ise her tur için harcanan enerjiyi ifade eder.

$R=\frac{E_{\text {total }}}{E_{\text {round }}}$

$E_{\text {round }}$, tek bir tur sırasında bir algılayıcı ağında tüketilen enerji olup denklem (7) olarak verilir.

$E_{\text {round }}=k_{\text {opt }}\left(2 N E_{\text {elec }}+N E_{D A}+\right.$

$l e_{a m p} d^{4}(B S)+N e_{f S} d^{2}(K B)$

$E_{\text {elec }}$, dügümün elektronik olarak verici veya alıcıyı çalıştırmak için bit başına enerji tüketimini, $e_{f s}$ ve $e_{a m p}$ sırasıyla boş alan ve çoklu yol için radyo amplifikatörünü türlerini ifade eder. $k_{o p t},{ }_{D A}, d(B S), d(K B)$, sirasiyla, optimum küme sayısı, küme yarıçapı, KB tarafından tüketilen veri toplama enerjisinin 
maliyeti, $\mathrm{KB}$ ve $\mathrm{BS}$ arasındaki ortalama mesafe ve küme üyeleri ile $\mathrm{KB}$ arasındaki ortalama mesafeyi ifade etmektedir [8,9,18] (Denklem $8,9)$.

$$
\begin{aligned}
& d(K B)=\frac{M}{\sqrt{2 \pi}} \\
& d(B S)=0.765 \frac{M}{2}
\end{aligned}
$$

Optimum küme sayısı $k_{\text {opt }}$, denklem (10)'daki gibi bulunur.

$k_{o p t}=\sqrt{\frac{N}{2 \pi}} d_{0} \frac{M}{d^{2}(B S)}$

Referans mesafesi $d_{0}$, denklem (11) olarak hesaplanır.

$d_{0}=\sqrt{\frac{e_{f s}}{e_{a m p}}}$

Önerilen modelde KB seçimi için olasıllklar, denklem (12) 'de verilmektedir. $E_{i}(r), i$. düğümün kalan enerjisini ifade etmektedir. Ayrıca çok-seviyeli heterojen ağ modelindeki KB seçim olasılığ 1 denklem (13)'deki gibi verilebilir $[9,18]$.

$p_{i}=\left\{\begin{array}{l}\frac{E_{i}(r) E_{0} p_{\text {opt }}}{E_{\text {avg }} E_{\text {total }}} \text { normal düğüm için }\left(\text { ĕger }\left(E_{i}(r)>T_{\text {limit }}\right)\right. \\ \frac{E_{i}(r) E_{0} p_{\text {opt }}(1+a)}{E_{\text {avg }} E_{\text {total }}} \text { gelişmiş düğüm için }\left(e \breve{g} e r\left(E_{i}(r)>T_{\text {limit }}\right) \quad(12)\right. \\ \frac{E_{i}(r) E_{0} p_{\text {opt }}(1+b)}{E_{\text {avg }} E_{\text {total }}} \text { süper düğüm için }\left(\text { ĕger }\left(E_{i}(r)>T_{\text {limit }}\right)\right.\end{array}\right.$

$p_{\text {coklu }}=\frac{p_{o p t}+N\left(1+a_{i}\right)}{\left(N+\sum_{i=1}^{N} a_{i}\right)}$

\section{Küme Başı Seçimi}

Kurulum aşamasından sonra, her algılayıcı dügümü kendisini o anki tur için bir $\mathrm{KB}$ adayı olarak belirler. Bu belirleme $i$. düğüm tarafindan sağlanır. 0 ile 1 arasında rastgele bir sayı seçilir. Seçilen sayı $T\left(K_{i}\right)$ eşiğinden düşük olduğunda, $i$. düğüm geçerli tur için bir KB olur. Önerilen yöntemdeki tüm algılayıcı düğümleri boyunca homojen enerji tüketimi sağlamak için, KB'ler algılayıcı düğümlerinin kalan ve ortalama enerjisini temel alan denklem (12)'ye göre seçilir. $T\left(K_{i}\right)$ eşik seviyesi denklem (14)'deki gibi seçilir $[8,9,18]$.

$G$, KB seçimi uygun düğüm grubunu içerir, Herhangi bir enerji alanından bir KB tarafindan tüketilen enerji, denklem (15)'de olduğu gibi hesaplanır.

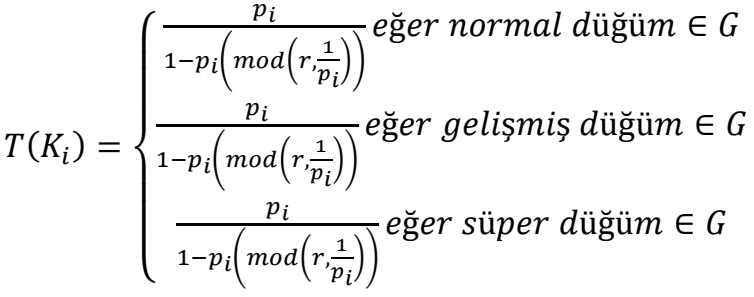

$$
\begin{aligned}
& E_{c h}=l E_{\text {elec }}\left(\frac{N_{n m l}+N_{a d}+N_{\text {sup }}}{k_{\text {opt }}}-1\right)+l e_{\text {amp }} d^{4}(B S)
\end{aligned}
$$

\section{Benzetim Kurulumu}

Bu çalışmada üç seviyeli heterojen KAA'lar için EDEEC ve SEED yöntemlerini avantajlarından yararlanılarak enerji-verimli kümeleme yöntemi önerilmiştir. Önerilen yöntem, EDEEC ve SEED protokolleriyle performans kıyasina tabi tutulmuştur. Performans analizleri MATLAB R2019a programlama kullanarak çeşitli benzetimlerce sonuçlandırılmıştır. KAA oluşturulurken, $(0,0)$ merkezli olarak konumlanmış bir BS ile $200 \times 200 \mathrm{~m}^{2}$ ve $500 \times$ $500 \mathrm{~m}^{2}$ boyutunda bir ağ alanına 100 ile 500 düğüm arasında değişen algılayıcı düğümleri rastgele dağıtılmıştır. Bu senaryoların amacı hem ağ yoğunluğunun hem de ăg boyutunun performansa etkisinin ölçülmesidir. Tüm algılayıcı düğümlerinin sabit konumda olduğu ve tüm düğümlerin sinyalleri arasındaki bozulma nedeniyle enerji kaybı olmadığı varsayılmıştır. Tüm benzetimlerde, benzetim şartları eşit olması açısından Tablo 1'deki parametreler kullanılmıştır. Örnek olarak, senaryolarda 100 düğümlü ve $200 \times 200 \mathrm{~m}^{2}$ ağ alanında önerilen modele göre oluşan heterojen kümeli ağ yapısı Şekil 2'de gösterilmiştir. Şekil 2'den de görüldüğü üzere $\mathrm{BS},(0,0)$ konumunda bulunmaktadır. Her bir kümede yıldızlı olarak tasvir edilen bir KB düğüm bulunmaktadır. Diğer dügümler de normal düğümleri temsil etmektedir. Tur sayısı arttıkça düğümlerin enerjileri azaldığından dolayı farklı renklerle gösterilmektedir. Şekil 3 ise Şekil 2'deki ağın kuşbakış1 olarak görüntüsünü vermektedir. Kuşbakışı görüntü uzaktan izleme ve takip etme gibi birçok amaç için kullanılabilir. 
Tablo 1. Benzetim parametreleri

Table 1. Simulation parameters

\begin{tabular}{|c|c|c|}
\hline Parametre tipi & Sembol & Değer \\
\hline $\begin{array}{l}\text { Amplifikatörün enerji } \\
\text { tükenmesi (Kısa } \\
\text { mesafe) }\end{array}$ & $e_{f s}$ & $\begin{array}{l}\text { 10nJ/bit } \\
/ m^{2}\end{array}$ \\
\hline $\begin{array}{l}\text { Amplifikatörün enerji } \\
\text { tükenmesi (Uzak } \\
\text { mesafe) }\end{array}$ & $e_{a m p}$ & $\begin{array}{l}0.0013 \mathrm{pJ} \\
/ \mathrm{bit} / \mathrm{m}^{4}\end{array}$ \\
\hline $\begin{array}{l}\text { Sinyali iletmek veya } \\
\text { almak için düğümün } \\
\text { elektronik devresinin } \\
\text { enerji tükenmesi }\end{array}$ & $E_{\text {elec }}$ & $50 \mathrm{~nJ} / \mathrm{bit}$ \\
\hline Veri toplama enerjisi & $E_{D A}$ & $\begin{array}{l}\text { 5nJ/bit } \\
\text { /signal }\end{array}$ \\
\hline Eşik uzaklık değeri & $d_{0}$ & $50 \mathrm{~m}$ \\
\hline $\begin{array}{l}\text { İstenilen KB olma } \\
\text { olsa1lığ1 }\end{array}$ & $p_{\text {opt }}$ & 0.2 \\
\hline Toplam tur say1s1 & $R$ & 5000 \\
\hline Veri boyutu (bit) & $l$ & 5000 \\
\hline A $\breve{g}$ boyutu & & $\begin{array}{l}250 * 250 \\
m^{2} \\
500 * 500 \\
m^{2} \\
\end{array}$ \\
\hline Alıcı düğüm konumu & & $(0,0)$ \\
\hline Toplam düğüm sayısı & $N$ & $100-500$ \\
\hline Normal düğüm sayısı & $N_{n m l}$ & $N * 55 / 100$ \\
\hline Gelişmiş düğüm sayısı & $N_{a d}$ & $N * 30 / 100$ \\
\hline Süper düğüm sayısı & $N_{\text {sup }}$ & $N * 15 / 100$ \\
\hline Düğüm dağıtımı & & Rastgele \\
\hline Küme yarıçapı & $M$ & $25 \mathrm{~m}$ \\
\hline $\begin{array}{l}\text { Normal düğümün } \\
\text { başlangiç enerjisi }\end{array}$ & $E_{0}$ & $0.25 \mathrm{~J}$ \\
\hline $\begin{array}{l}\text { Gelişmiş düğümlerin } \\
\text { normal düğümlerden } \\
\text { kaç katı enerjiye sahip } \\
\text { olduğu }\end{array}$ & $\mathrm{a}$ & 1 \\
\hline $\begin{array}{l}\text { Süper düğümlerin } \\
\text { normal düğümlerden } \\
\text { kaç katı enerjiye sahip } \\
\text { olduğu }\end{array}$ & $\mathrm{b}$ & 2 \\
\hline $\begin{array}{l}\text { Gelişmiş düğümlerin } \\
\text { kesir katsayısı }\end{array}$ & $f_{0}$ & 0.005 \\
\hline $\begin{array}{l}\text { Süper düğümlerin } \\
\text { kesir katsayıs1 }\end{array}$ & $f_{1}$ & 0.006 \\
\hline
\end{tabular}

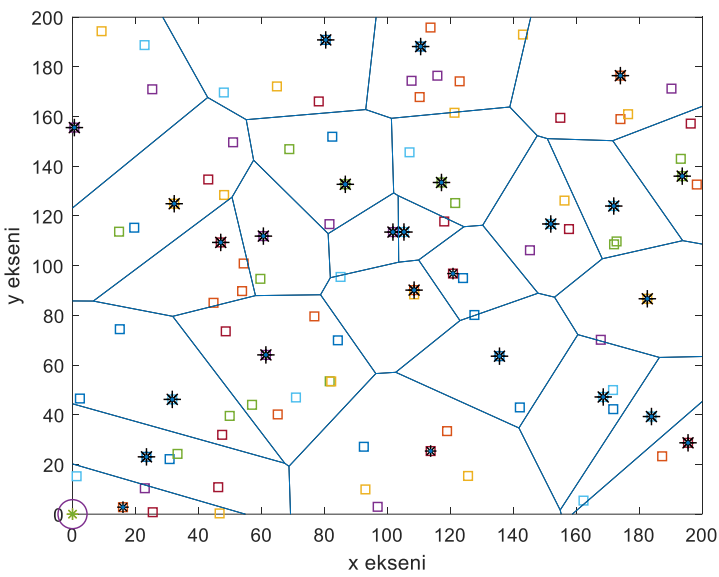

Şekil 2. Birkaç turdan sonra kümeli heterojen ă̆ yapısı (100 düğüm için)

Figure 2. A clustered heterogeneous network structure after several rounds (for 100 nodes)

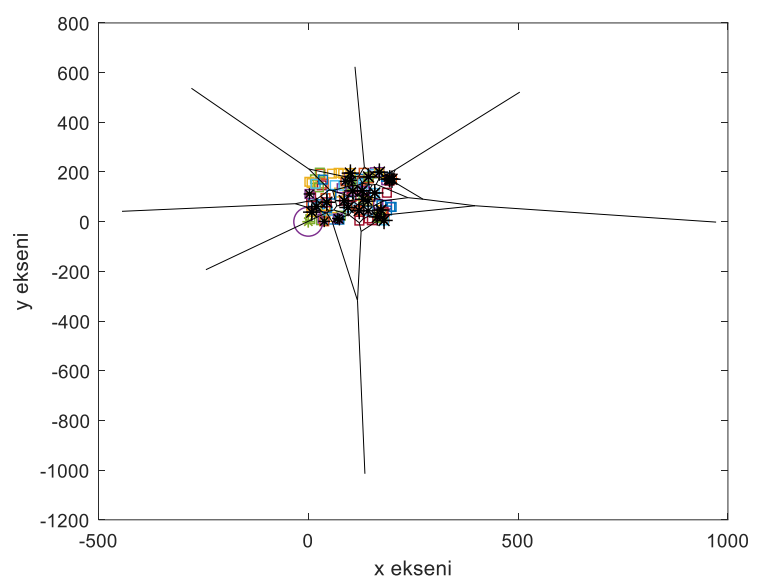

Şekil 3. Kümeli heterojen ăg yapısının kuşbakışı görünümü (100 dügüm için)

Figure 3. A panoramic view of the clustered heterogeneous network structure (for 100 nodes)

Şekil 4, 500 düğümlü ve $200 \times 200 \mathrm{~m}^{2}$ ağ alanında önerilen modele göre oluşan heterojen kümeli ağ yapısını göstermektedir. Buradaki amaç ise ağ yoğunluğu fazla olan ağların benzetimini yapmaktır. Şekil 5 ise Şekil 4'deki ağ yapısının kuşbakışı görünümünü sunmaktadır. 


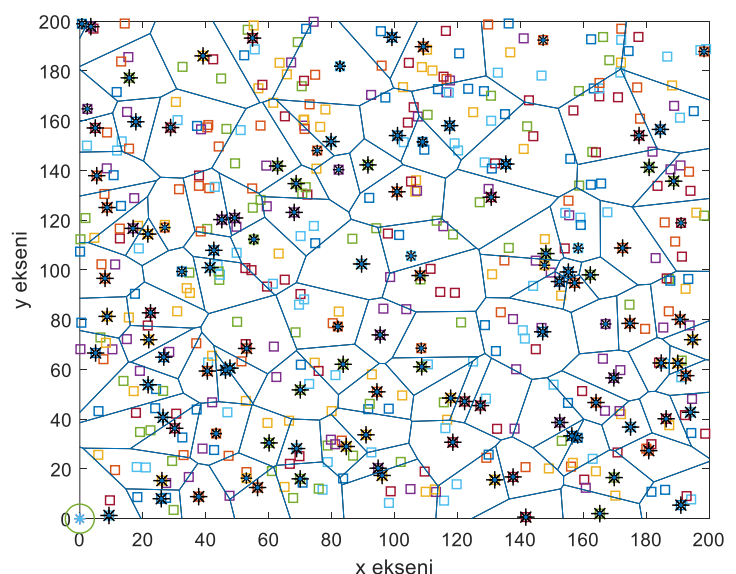

Şekil 4. Birkaç turdan sonra kümeli heterojen ă̆ yapısı (500 düğüm için)

Figure 4. A clustered heterogeneous network structure after several rounds (for 500 nodes)

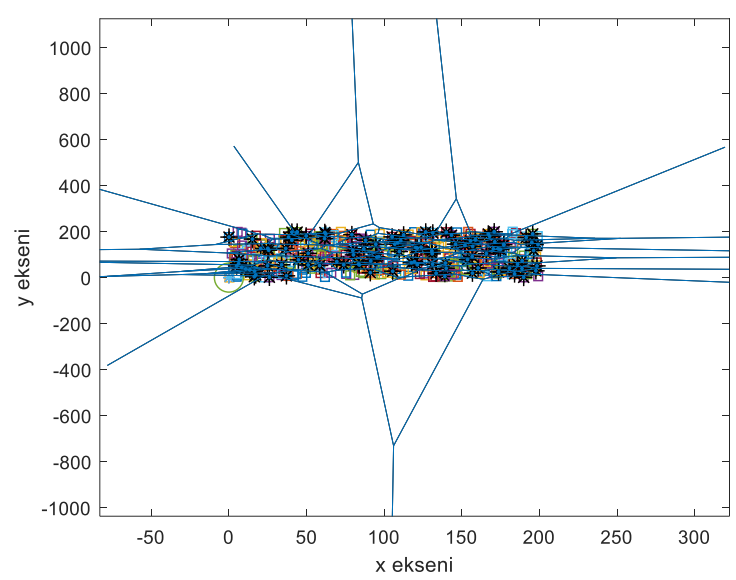

Şekil 5. Kümeli heterojen ă̆ yapısının kuşbakışı görünümü (500 düğüm için)

Figure 5. A panoramic view of the clustered heterogeneous network structure (for 500 nodes)

\section{Benzetim Sonuçlarının İrdelenmesi}

$\mathrm{Bu}$ bölümde çalışmada elde edilen benzetim sonuçları irdelenmiştir. Tüm yöntemlerin analizleri için kullanılan kalite performans metrikleri ağdaki canlı düğümler, KB'den BS'ye gönderilen paket sayısı ve ortalama KB sayısıdır.

\section{Ağdaki Canlı Düğüm Sayısının İrdelenmesi}

Canlı düğümler metriği, tur sayısı arttıkça canlı düğümlerin sayısının ölçümüdür. Enerjisi biten düğümler ölür ve canlı düğüm sayısı azalır. $\mathrm{Bu}$ çalışmada, ağda canlı düğüm sayısının etkisi,
$200 \times 200 \mathrm{~m}^{2}$ ve $500 \times 500 \mathrm{~m}^{2}$ ağ alanına sahip ağlar için iki farklı benzetim olarak gerçekleştirilmiştir. $\mathrm{Bu}$ benzetim sonuçları sırasıyla Şekil 6 ve 7'de verilmiştir. Şekil 6'da gözlemlendiği üzere, en uzun ağ ömrü 3060. turun üzerinde olarak önerilen yöntem çalıştırıldığında elde edilmiştir. Yani ağdaki 100 dügüm tamamen 3060. turdan sonra enerjisini yitirmiştir. Önerilen yöntem, SEED ve EDEEC yöntemleri çalıştırıldığında sırasıyla, ilk düğüm 1087, 1259 ve 1494. turda ölmektedir. Bu anlamda önerilen metot kıyaslanan algoritmalar arasında en iyi performans göstermiştir. Şekil 7'den de anlaşılacağı üzere, EDEEC, SEED ve önerilen yöntemle ilk düğüm sırasıyla 125, 235 ve 223. turda ölmüştür. Son dügüm ölümü ise önerilen ve SEED protokolünde benzer performans göstermiştir. Ancak önerilen yöntem EDEEC yönteminden daha iyi sonuç vermiştir. Şekil 6 ve 7'deki benzetim sonuçları kıyaslandığında ağ boyutu artınca ağ ömrünün azaldığ1 görülmektedir.

\section{KB'den BS'ye gönderilen veri paketi sayısının İrdelenmesi}

$\mathrm{Bu}$ performans metriğiyle, KB'lerden $\mathrm{BS}^{\prime} \mathrm{ye}$ gönderilen toplam paket sayısı dikkate alınır. Şekil 8 ve 9, tur sayına göre BS'ye iletilen toplam paket sayısını göstermektedir. Şekil 8'den de görüldüğ̈̈ üzere önerilen yöntem, SEED ve EDEEC yöntemleri çalıştırıldığında BS'ye iletilen paket sayısı sırasıyla, yaklaşı $10.5 \times 10^{4}$, $7.3 \times 10^{4}$ ve $3 \times 10^{4}$ dir. $\mathrm{Bu}$ anlamda en iyi paket teslimatı önerilen yöntemle sağlanmıştır. Şekil 9'dan da anlaşılacağı üzere ağ boyutu artınca paket teslimatı tüm protokoller için düşmektedir. Aslinda hem tur sayıs hem de iletilen paket sayısı azalmaktadır.

\section{Ortalama KB sayısının İrdelenmesi}

$\mathrm{Bu}$ performans metriği ile ortalama KB sayısının ölçülmesi hedeflenmiştir. Bu çalışmada, her senaryo için 50 benzetim gerçekleştirildiği için ortalama KB sayısını esas alınmaktadır. Şekil 10 ve 11, tur sayısına göre ortalama KB sayısını göstermektedir. 100 dügüumlü bir ağda yaklaşık 22 adet $\mathrm{KB}$ düğümlü heterojen ağ yapısı olmasına rağmen canlı düğüm sayısı azaldıkça KB sayısı da azalmaktadır. Şekil 10'dan görüldüğü üzere, önerilen yöntem ile en yüksek 
KB sayılı ve en uzun turlar için ağ ömrüne sahip KAA oluşmaktadır. Önerilen yöntem hibrid bir yaklaşım benimsediğinden ötürü, SEED ve EDEEC protokollerine göre üstün performans göstermektedir. Şekil 11 'den de görüldügüu üzere ağ boyutu artınca tüm yöntemler için ortalama KB sayısı azalmaktadır. Şunu belirtmek gerekirse, ağdaki $\mathrm{KB}$ sayısı azalınca dügümler arasındaki uzaklık artacağından ötürü hem veri kaybı hem de verimlilik azalmaktadır.

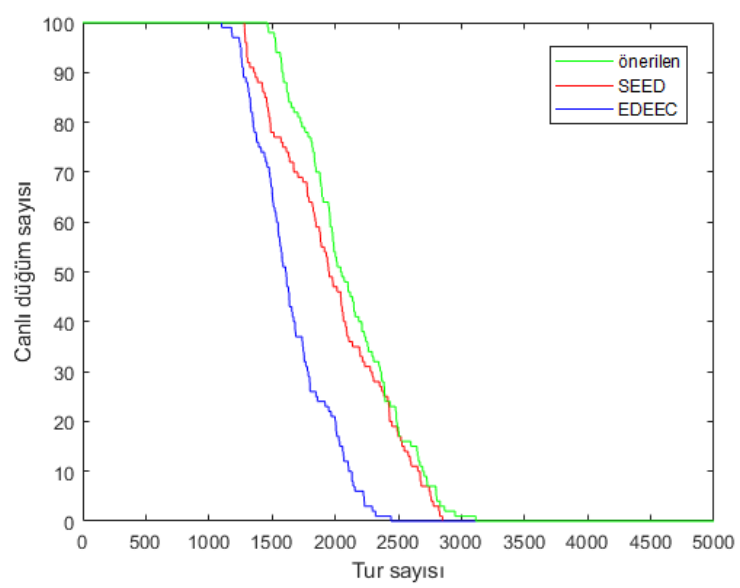

Şekil 6. Ăgda canlı düğ̈̈̈m sayısı $\left(200 \times 200 m^{2}\right)$

Figure 6. Number of live nodes in the network $\left(200 \times 200 \mathrm{~m}^{2}\right)$

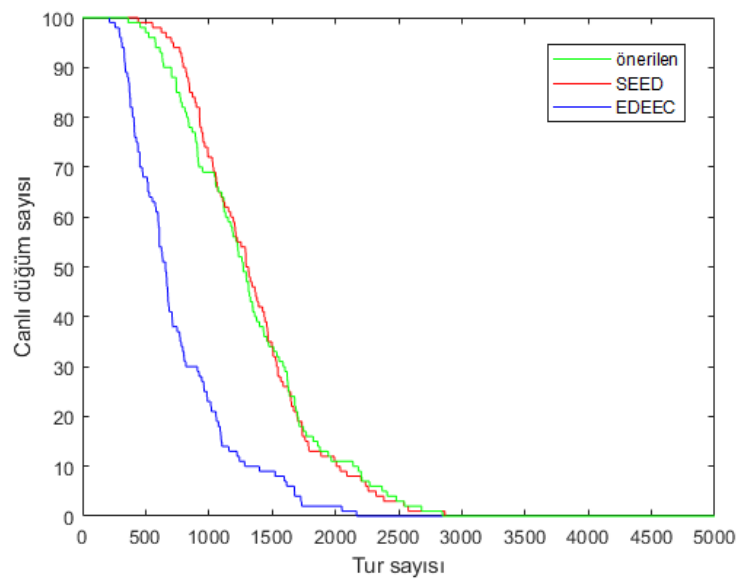

Şekil 7. A ̈̆gda canlı düğüm sayısı $\left(500 \times 500 m^{2}\right)$

Figure 7. Number of live nodes in the network $\left(500 \times 500 \mathrm{~m}^{2}\right)$

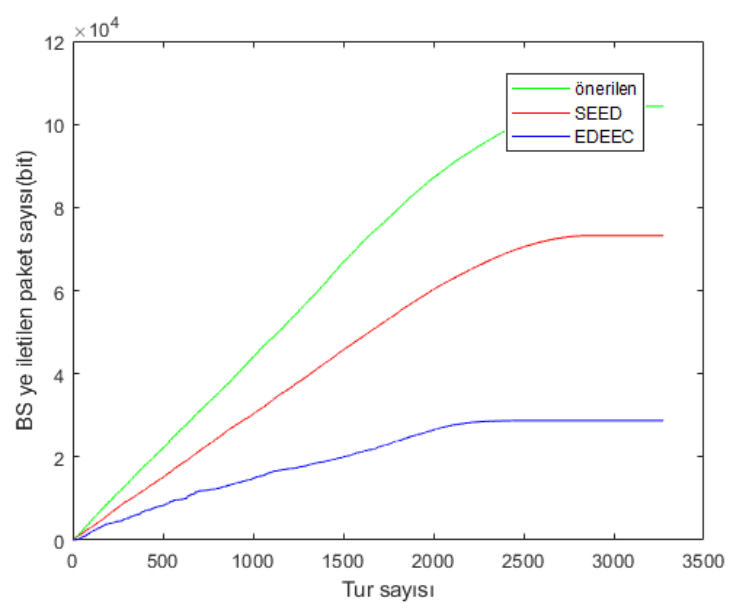

Şekil 8. BS'ye iletilen paket sayısı $\left(200 \times 200 \mathrm{~m}^{2}\right)$

Figure 8. Number of packets forwarded to BS $\left(200 \times 200 \mathrm{~m}^{2}\right)$

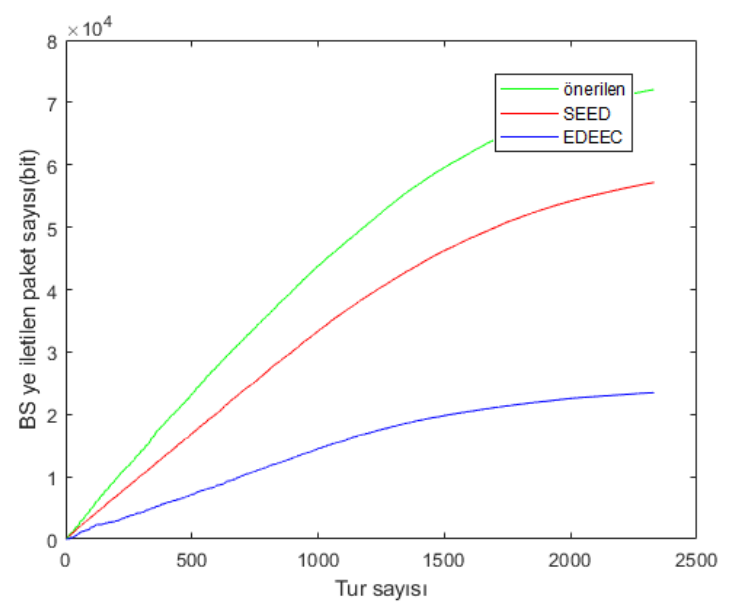

Şekil 9. BS'ye iletilen paket sayısı $\left(500 \times 500 \mathrm{~m}^{2}\right)$

Figure 9. Number of packets forwarded to BS $\left(500 \times 500 \mathrm{~m}^{2}\right)$

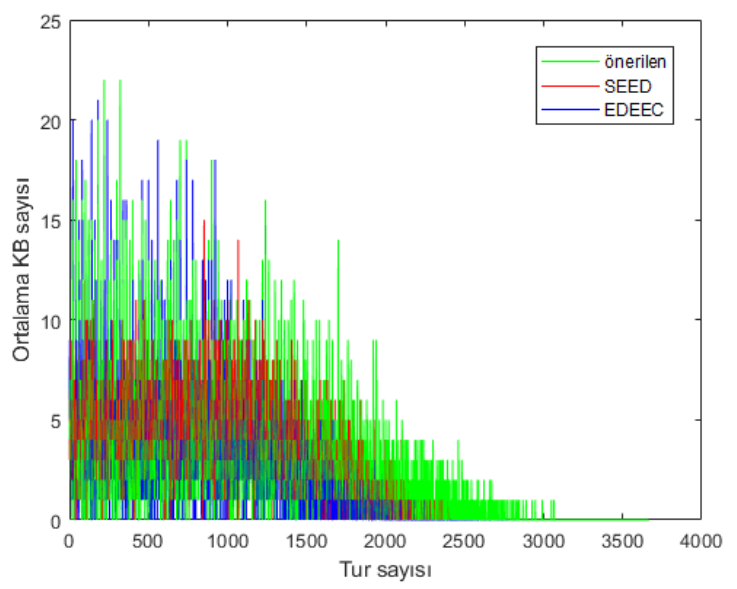

Şekil 10. Ortalama KB sayısı $\left(200 \times 200 \mathrm{~m}^{2}\right)$

Figure 10. Average number of $\mathrm{CHs}$ $\left(200 \times 200 \mathrm{~m}^{2}\right)$ 


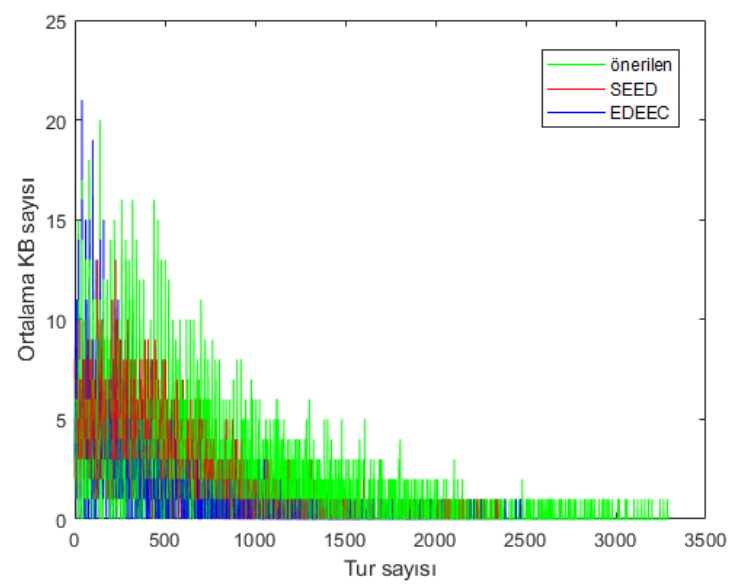

Şekil 10. Ortalama KB sayısı $\left(500 \times 500 \mathrm{~m}^{2}\right)$

Figure 10. Average number of CHs $\left(500 \times 500 \mathrm{~m}^{2}\right)$

\section{Sonuç}

$\mathrm{Bu}$ çalışmada, enerji-verimli heterojen KAA'larda hibrid kümeleme protokolü sunulmuştur. Önerilen bu protokol, EDEEC protokolü gibi bir üç seviyeli ağ modeline ve SEED protokolüne benzer bir veri iletim-toplama mekanizmasına sahiptir. Önerilen protokol, EDEEC ve SEED protokolleriyle performans kıyasına tabi tutulmuştur. Tüm protokoller, ağ ömrü boyunca canlı dügüumler, BS'ye iletilen paket sayısı ve ortalama KB sayısı açısından analiz edilmiştir. Benzetim sonuçları, önerilen yöntemin, ilgili parametreler açısından diğer yöntemlere göre üstünlüğünü göstermektedir. Önerilen yöntem özellikle BS'ye iletilen paket sayısı bakımından diğer yöntemlerden iyi sonuçlar doğurmuştur. $\mathrm{Bu}$ anlamda, paket teslimatı daha verimli gerçekleştirilmiştir. Gelecek çalışmalarda, KAA'lar için çoklu mobil alıcı dügüum tabanlı heterojen yönlendirme ve kümeleme algoritmaları önerilmesi planlanmaktadir.

\section{Kaynaklar}

[1] Vancin, S. and Erdem, E., (2017). Implementation of the vehicle recognition systems using wireless magnetic sensors. Sadhana Springer, 42(6), 841-854.

[2] Vancin, S., Erdem, E., (2018). Threshold Balanced Sampled DEEC Model for Heterogeneous Wireless Sensor Network, Wireless Communication and Mobil Computing, 6, 1-12.

[3] Burrell, J., Brooke, T., Beckwith, R., (2014). Vineyard Computing: Sensor Networks in Agricultural Production. International Journal of Computer Applications (0975 - 8887), 97(7), 9 - 16.
[4] Yalçın, S., Erdem, E., (2019). Bacteria Interactive Cost and Balanced-Compromised Approach to Clustering and Transmission Boundary-Range Cognitive Routing in Mobile Heterogeneous Wireless Sensor Networks, Sensors 2019, 19(4), 130.

[5] Lee, J. Y., dong Jung, K., Lee, D., (2015). The routing technology of wireless sensor networks using the stochastic cluster head selection method. International Journal of Control and Automation, 8(7), 385-394.

[6] Muhammad, A. (2016). Adaptive energy-efficient clustering path planning routing protocols for heterogeneous wireless sensor networks. Sustainable Computing: Informatics and Systems, 12, 57-71.

[7] Krishna, K. H., Babu, Y. S., Kumar, T., (2016). Wireless Network Topological Routing in Wireless Sensor Networks, Procedia computer science, 79, 817-826.

[8] Saini, P., Sharma, A. K. (2010). E-DEEC- Enhanced Distributed Energy Efficient Clustering Scheme for heterogeneous WSN. in: 2010 1stInternational Conference on Parallel, Distributed and Grid Computing, pp. 914-919.

[9] Ahmet, G., Zou, J., Fareed, M.M.S., Zeeshan, M.,(2015). Sleep- awake energy efficient distributed clustering algorithm for wireless sensor networks.". Computer and Electrical Engineering, 56, 385-398.

[10] Heinzelman, W. R., Chandrakasan, A. P., Balakrishnan, H., (2000). Energy efficient communication protocol for wireless micro sensor networks. in: Proceedings of the 33rd Hawaii International Conference on System Sciences (HICSS-33), January 2000.

[11] Lindsey, S., Raghavenda, C. S., (2002). PEGASIS: Power efficient gathering in sensor information systems. in: Proceeding of the IEEE Aerospace Conference, Big Sky, Montana, pp. 1-6.

[12] Singh, J., Pratap Singh, B., Shaw, S. (2014). A New LEACH-based Routing Protocol for Energy Optimization in Wireless Sensor Network", 2014 5th International Conference on Computer and Communication Technology, pp. 181-186.

[13] Younis, O., Fahmy, S., (2004). HEED: A hybrid, energy efficient, distributed clustering approach for ad hoc sensor networks, IEEE Transactions on Mobile Computing, 3(4), 660-669

[14] Smaragdakis, G., Matta, I., Bestavros, A., (2004). SEP: A Stable Election Protocol for clustered heterogeneous wireless sensor network. in: Second International Workshop on Sensor and Actor Network Protocols and Applications (SANPA), 97(7), $1-11$.

[15] Qing, L., Zhu, Q., Wang, M. (2006). Design of a distributed energy-efficient clustering algorithm for heterogeneous wireless sensor network. ELSEVIER, Computer Communications, 29, 2230- 2237.

[16] Elbhiri, B., Saadane, R., El Fkihi, S., Aboutajdine, D. (2010). Developed Distributed Energy-Efficient Clustering (DDEEC) for heterogeneous wireless 
sensor networks.in: 5th International Symposium on I/N Communications and Mobile Network (ISVC), pp. 1-4.

[17] Javaid, N., Qureshi, T. N., Khan, A. H., Iqbal, A., Akhtar, E., Ishfaq, M. (2013). EDDEEC: Enhanced Developed Distributed Energy-Efficient Clustering for Heterogeneous Wireless Sensor Networks. Procedia Computer Science, 19, 914-919.

[18] Vancin, S., Erdem, E., (2017). Performance analysis of the energy efficient clustering models in wireless sensor. 24th IEEE International Conference on Electronics, Circuits and Systems (ICECS), Batumi, Georgia. pp. 247-251.

[19] Gambhir, A.,Payal,A.,Arya,R. (2018). Performance analysis of artificial bee colony optimization based clustering protocol in various scenarios of WSN. International Conference on Computational Intelligence and Data Science (ICCIDS 2018).132, 183-188. 